\title{
Socio-Economic Factors Influencing the Adoption of Improved Sorghum Varieties in Oromia Region, Mieso District
}

\author{
Samson Moges \\ Ethiopian Institute of Agricultural Research, Chiro National Sorghum Research and Training Center, P.O.Box: 190, Chiro, Asebe \\ Teferi, Ethiopia.
}

How to cite this paper: Samson Moges. (2022) Socio-Economic Factors Influencing the Adoption of Improved Sorghum Varieties in Oromia Region, Mieso District. International Journal of Food Science and Agriculture, 6(1), 17-23. DOI: 10.26855/ijfsa.2022.03.004

Received: December 1, 2021

Accepted: December 25, 2021

Published: January 14, 2022

"Corresponding author: Samson Moges, Chiro National Sorghum Research and Training Center, Chiro, Asebe Teferi, Ethiopia.

Email: mogess707@gmail.com

\begin{abstract}
Sorghum is an important crop in Mieso district. It has been producing traditionally using oxen plowing, sowing by broadcasting and threshing by animals. The grain is use for human consumption and the biomass used for animal fodder. The use of improved high yielding crop varieties by farm households remains an option to increase agricultural production and ensure food security in developing countries. The aim of this study is to identify the socio-economic factors that influence farmers' decision to adopt improved Sorghum varieties by farmer households' in Mieso district. 160 sample households (100 adopters and 60 non-adopters) selected from six PAs of the district were interviewed using structured interview schedule. Qualitative data were collected using group discussion. Data analysis were done using Chi-square and logit linear regression were employed to analyze the influence of different variables on probability of adoption of improved sorghum varieties, using a software called STATA 12. The results of the econometric model indicated that farm size, education level, number of active labor of the household, attending field day programs, frequency of contact with extension agent and access to information and number of livestock significantly influenced at one percent probability level on adapter. Whereas, age of household head and number of dependent member of the household has negative influence on adoption of improved Sorghum varieties. The findings of the study implies that strengthening extension service and increasing farmers engagements of formal education, as most of the households had no formal education, the extension program should be intended to the less educated farmers. In addition, properly designed field demonstration should be need attention to improve the adoption rate of improved Sorghum varieties.
\end{abstract}

\section{Keywords}

Adoption, Logit model, Improved Sorghum Varieties

\section{Introduction}

Ethiopians have dominantly practiced a mixed agricultural activity. Their livelihood is mainly based on tilling and herding of mammals and birds with little transformation for a long period of time in history because of religion and cultural preference [1]. However, agriculture is still the backbone of the country which represents about $33.88 \%$ of its GDP and around 80-85\% Ethiopians are engaged in agriculture, mainly in subsistence and rain-fed farming and livestock production. Despite this, around 35\% of the population does not have enough nutrition food to eat [2]. The agricultural sector of Ethiopia has shown remarkable resilience over many centuries though it is now increasingly failing. 
The country is known for the regular food shortage that occurred due to droughts, sudden outbreaks of natural disasters, pests, lack of rainfall, and shortage of technological advancement in the past centuries. Therefore, improving the implementation of extension service in agronomic practices, forestation, protection of livestock and crop plants, accessing financial support, and accessing time-based markets can improve the livelihood of the community [3]. Ethiopia's agriculture heavily relies on oxen plow and rain-fed that by neglecting other alternative technologies since the time of the Neolithic era [4].

The major cereal crops cultivated in the country are tef (3,023,284 ha) maize (2,128,949 ha), Sorghum (1,896,389 ha), wheat (1,696,907 ha), and Barley (951,993.2 ha). Pulses are important grain crops for cash earning as well as for food [5]. Sorghum is an important crop in lowland and intermediate altitudes in Ethiopia, covering an area of 1,896,389 ha with production of 4.3MT. The majority of the product consumed in rural households. Only $13 \%$ of the grain marketed and $7 \%$ is processed. Yields are 2.5 T/ha., which is low by comparison with the crop's potential [6].

So far, the research system of the country has developed and released several yield increasing and drought resistant improved Sorghum varieties. According to Ethiopian Agricultural Research Organization [7], 23 improved Sorghum varieties had been released to the users nationally.

Even though, various development stakeholders have also been undertaking several interventions of improved Sorghum varieties promotion activities so far, still now the released varieties not adopted by the famers as required. According to planning and program section report of Mieso district Agricultural Office [8], only 7\% of the cultivated land is covered by improved varieties this shows that there is confrontation on using improved sorghum varieties in cropping year of 2019/2020. Therefore, this study is need, to assess what socio economic factors that affecting adoption of improved Sorghum varieties in the study area.

\section{Materials and Methods}

\subsection{Study Area}

The study conducted at Mieso district. Mieso is located $302 \mathrm{~km}$ east of Addis Ababa. Mieso district cover an area of 186,716 ha and it has 31 rural and two dwellers town including district town with total of 31,456 household members; According to the [2] population projection, Mieso district have quantified 144,750, of which 82,796 and 61,954 are male and female respectively; geographically, the district is located between $40^{\circ} 9^{\prime \prime} 30.1^{\prime} \mathrm{W}$ and $40^{\circ} 56^{\prime \prime} 44^{\prime} \mathrm{E}$; and: $9^{\circ} 19^{\prime \prime} 52^{\prime} \mathrm{N}$ and $8^{\circ} 48^{\prime \prime} 12 \mathrm{~N}$. attitudinally, the district ranges from 1,107 to 2,900m.a.s.l, but most of the district is found at about 1,400m.a.s.l. The average land holding (cultivable land) in this farming system is 1.5 ha per household. However, the proportion of total land to total rural households in this farming system is, $1.5 \mathrm{ha}$.

There are two main cropping seasons in the area: belg and meher. The belg season begins from late April to late March/early April where sorghum has planted. The meher cropping season begins late June and continues up to September $1^{\text {st }}$. Crops like haricot bean and maize early mature Sorghum varieties planted in the meher season.

\subsection{Sampling Technique and Data Collection}

Primary data were used for this study. The primary data were collected based on 2020 cropping season using detailed structured questionnaires, with the assistance of an enumerator. The interview methods of data collection were used.

A purposive sampling design were employed to select survey sites. Because, there have existed wide difference of adoption practices between agro pastoralists and pastoralist in the district. Meiso broadly divided into agro pastoral and pastoral farming system. The agro pastoralists assumed they practiced crop production. Therefore, it has imperative to select agro pastoral areas purposively than pure pastoral PAs.

Sample size was determined to be 160, of which 100 respondents were adopters and 60 respondents in the non-adopters group. Among the 25 agro pastoral PAs, Six agro pastoral PAs were selected using simple random system, for primary data collection process.

Data collected: Age of the household head (year), Farm size, Education level, Sex of the household head, Availability Labor, Livestock ownership, Information Access, Engagement of off farm activities, Access to credit, Access to Market, Dependent household members, Participation in on-farm trials and demonstrations, frequency contact with extension agent. The values were binary in nature 1 indicating farmers who adopted improved sorghum varieties while, 0 indicating farmers that did not adopted improved sorghum varieties.

\subsection{Model Specification}

A Linear Probability Model (LPM): adoption of improved sorghum varieties. In a regression model, in which the dependent variable is binary/dichotomous in nature taking the value 1 and 0 , the use of this model becomes a major problem. The predicted value may fall outside the required range of 0 to1 probability value. Thus, Many Dichotomous (binary) logistic regressions used to achieve this objective, which is to evaluate the factors influencing the adoption of im- 
proved sorghum varieties. Since the adoption of improved sorghum varieties is a dichotomous or binary dependent variable, with the option of either adoption or non-adoption, the binary logistic regression model used as the most appropriate tool to investigate how each independent variable affects the probability of the occurrence of events. The logistic regression model explores the socio-economic, institutional and spatial factors influencing the adoption of improved sorghum varieties. Thus, it helps to explore the degree and direction of relationship between dependent and independent variables in the adoption of improved sorghum varieties. Particularly the value 1 was indicates as farmers adopting improved sorghum varieties, while 0 indicates farmers not adopting improved sorghum varieties. Binary logistic regression is a type of regression model where the dependent variable is converted into dichotomous/binary variables coded 0 and 1. The model uses Maximum Likelihood Estimation (MLE) procedure. The advantage of this model is that the probabilities are bound between 0 and 1 . Logit model converts estimated cumulative distribution, therefore eliminating the interval 0 and 1 . Unlike the Ordinary Least Square (OLS), although it can be use to estimate binary or dichotomous natured models, certain assumptions of a classical regression model will violate. Such as non-normality of the disturbance, heteroscedastic variance of the disturbance and a questionable value of $\mathrm{R}^{2}$ as the measure of goodness of fit [8] This eventually expresses itself as follows;

$$
Y_{1}=\beta_{0}+\beta_{1} X_{2}+U
$$

models used in adoption studies fails to meet the statistical assumptions necessary to validate the conclusion based on the hypothesis tested [8] However, in order to overcome the problem associated.

With LMP, Logit or Probit models have recommended [9].

The Logistic cumulative probability function can express as.

$$
P_{I}=E\left[y=\frac{1}{x}\right]=\frac{1}{1+e^{-\left(\hat{a}_{0}+\hat{a}_{1} X_{1}\right)}}
$$

For ease of expression, one can rewrite the equation as;

$$
P_{i}=\frac{1}{1+e^{-z}}=\frac{e^{z}}{1+e^{z}}
$$

Where $P_{i}$ is the probability that the person adopted improved sorghum varieties

$$
Z i=\hat{\mathrm{a}}_{0}+\hat{\mathrm{a}}_{1} X_{i}+\ldots+\hat{\mathrm{a}}_{n} X_{n}
$$

$e$ is represents the base of the natural logarithms.

$\mathrm{Z}$ is ranges from $-\infty$ to $+\infty$

Although $\mathrm{Z}$ is a linear combination of variables that have both upper and lower bound, none will used as the variable $Z$. This is because the value of $Z$ will depend on the value of the unknown parameters $\beta$ s. To obtain the value of $Z$, the likelihood of observing, the sample will be formed by introducing a dichotomous response variable $Y$, such that;

$\mathrm{Y}_{\mathrm{i}}=1$ if household adopt improved sorghum varieties invariably; 0 if household do not.

$\mathrm{P}$ is ranges from 0 and 1

$\mathrm{Pi}$ is nonlinearly related to $\mathrm{Zi}$ (i.e. $\mathrm{Xi}$ )

Since $\mathrm{Pi}$, which is the probability of adopting improved sorghum is given as equation (3.4),

Then (1-Pi), the probability of not adopting improved sorghum can be expressed as,

$$
1-P_{i}=\frac{1}{1+e^{Z_{I}}}
$$

Therefore, we can write

$$
\frac{P_{i}}{1-P_{i}}=\frac{1+e^{Z}}{1+e^{-Z}}=e^{Z}
$$

Taking the natural log of equation (3.5) will give

$$
\mathbf{L i}=\ln \left[\frac{P_{i}}{1+P_{i}}\right]=Z_{i}=\hat{a}_{0}+\hat{a}_{1} X_{1}+\ldots+\hat{a}_{n} X_{n}
$$

Where $\mathrm{Li}=\log$ of the odds ratio, not only in $\mathrm{X}$, but also in linear parameters. It called the logit or logit probability model. This implies that the logistic model explained in the equation is based on the logit of $Z_{i}, Z_{i}=$ Stimulus index

The logit model selected for this study because the dependent variable is dichotomous in nature and the computation will be easier. As mentioned earlier, the adoption or non-adoption of improved Sorghum varieties addressed as a decision involving binary/dichotomous response variable. Those socio-economic and institutional factors influencing agro-pastoralist's adoption or non-adoption of improved sorghum varieties includes the following: Age of the household head, Sex household, Farm size, Labor availability, Participation in on-farm trials and demonstrations, Livestock ownership, information access, frequency to contact extension agent, education leve, engagement of off farm activities, dependent members, market access and finally access to credit/loans. In this study, the focal point was farmers decision to adopt improved sorghum varieties by seeking to quantify the probabilities of socio-economic factors influencing the 
decision to adopt improved sorghum varieties by the list obtained from the agricultural development program frames adopting and not adopting improved sorghum varieties.

The effect of a set of explanatory variables on adoption of improved sorghum varieties were specified using the following expression

$$
\begin{aligned}
& \text { Adoption }=\mathbf{f}\left(\mathbf{X}_{1}, \mathbf{X}_{2}, \mathbf{X}_{3}, \mathbf{X}_{4}, \mathbf{X}_{5} . \quad . \quad ., \mathbf{X}_{\mathrm{n}}\right) \\
& \boldsymbol{Y}=\hat{\mathrm{a}}_{\mathbf{0}}+\hat{\mathrm{a}}_{\mathbf{1}} \boldsymbol{X}_{\mathbf{1}}+\hat{\mathrm{a}}_{\mathbf{2}} \boldsymbol{X}_{\mathbf{2}}+\hat{\mathrm{a}}_{3} \boldsymbol{X}_{\mathbf{3}}+\hat{\mathrm{a}}_{\mathbf{4}} \boldsymbol{X}_{\mathbf{4}}+\ldots+\mathrm{a}_{13} \boldsymbol{X}_{\mathbf{1 3}}+\mu \ldots .
\end{aligned}
$$

Where $\mathrm{Y}=\mathrm{a}$ dichotomous response variable such that; $\mathrm{Y}=1$ If farmers adopt improved sorghum varieties and 0 if farmers do not.

Age of the household head (year), Farm size, Education level, Sex of the household head, Availability Labor, Livestock ownership, Information Access, Engagement of off farm activities, Access to credit, Access to Market, Participation in on-farm trials and demonstrations, frequency contact with extension agent.

$\mu=$ Disturbance term or error term which is normally indicated as zero mean and variance $\hat{a}_{1}, \hat{a}_{2}, \hat{a}_{3}, \ldots$., $\hat{\mathrm{a}}_{13}$ are the coefficients of the independent variables. The coefficient of the regression model were estimated using the maximum likelihood estimating the socio-economic and institutional factors influencing the adoption of improved Sorghum varieties.

\subsubsection{Linear regression model}

This model has a high ability to incorporate the effects of each independent variable on the dependent variable. The extent of adoption of improved Sorghum varieties were measured the area where cover by different crop varieties by individual farmers, influenced by a set of independent variables specified in the following model:

$$
Y=b_{0}+b_{1} x_{1}+b_{2} x_{2}+\ldots+b_{n} x_{n}
$$

Where $\mathrm{Y}$ is the dependent variable, is the area under the improved

Sorghum varieties.

$\mathrm{b} 0$ is the intercept,

b1, b2, ... , bn are the coefficients of the independent variables

$\mathrm{X} 1-\mathrm{Xn}$.

Using the statistical and econometric models described above, the research was interpreted the results employing computation and explanation. Computers analyzing and computers of software STATA 12 employed to achieve the objective of the study.

\section{Results and Discussion}

Field day Participations: From the total sample households 26 (16.25\%) of agro pastoralists have attended field days at different level of frequency while the majority of the farmers $25(25 \%)$ did not attended field day programs (Table.1). The relationship between field days participation and adoption status, chi-square $\left(\chi^{2}=6.087\right)$ shows that there is significant association between Adaptor and non adopter categories. The result of this study is in agreement with the findings of $[9,16]$, at the event, neighboring farmers will get chance to observe the potential of new technologies. This platform may make possible and enhance the adoption level of farmers.

Access to information: There were significant differences among the sample respondents on adoption of improved sorghum varieties. Farmers who have information from different source, such as, from active farmers, Radio, Researcher, Development Agent, etc, highly have tendency of adopted new technologies. Framers were found to access information with varying proportion being $88(88 \%)$ and 33(55\%) from their groups respectively. The percentage difference on access to information was statistically tested and it was found to be significant at $1 \%\left(\chi^{2}=12.175\right)$. This hinted that there was systematic association between access to information and adoption of improved sorghum varieties.

Educational Level: Among the sample households 62.5\% were illiterates and 37.5\% were literates, which means attending regular school education (Table 1$)$. The result of chi-square-test $\left(\chi^{2}=13.196, \mathrm{P}=0.005\right)$ this value revealed that, there is significant relationship between education and adoption of improved sorghum varieties. Educated farmers are more able to process information and search for appropriate technologies to reduce the risk of climate change and increase their production. The result of this study is in agreement with the studies conducted by [10, 17] who reported significant relationship between education and the adoption of improved maize production package.

\subsection{Factors affecting the adoption of improved Sorghum Varieties}

Table 2 below shows that out of thirteen variables entered in to the binary logit model, ten variables were found to have a significant influence on the probability of adoption. These variables include Age, education level, farm size, Livestock own, active labor size and frequency to contact with extension agent at $1 \%$ and access to information and field day participation at $5 \%$ and dependent member, off-farm activities at $10 \%$ found to a significant influence on the probability of improved Sorghum varieties adoption. 
Table 1. Distribution of Sample Respondents and Chi-Square Value

\begin{tabular}{|c|c|c|c|c|c|c|c|}
\hline \multirow[b]{2}{*}{ Variables } & \multicolumn{2}{|c|}{ Adopters (N=100) } & \multicolumn{2}{|c|}{ Non-adopters $(\mathbf{N}=\mathbf{6 0})$} & \multicolumn{2}{|c|}{ Total $(\mathrm{N}=160)$} & \multirow[b]{2}{*}{$x^{2}$} \\
\hline & Frequency & $\begin{array}{c}\text { Relative Fre- } \\
\text { quency \% }\end{array}$ & Frequency & $\begin{array}{c}\text { Relative Fre- } \\
\text { quency \% }\end{array}$ & Frequency & $\begin{array}{c}\text { Relative Fre- } \\
\text { quency \% }\end{array}$ & \\
\hline \multicolumn{8}{|l|}{ Gender } \\
\hline Male & 68 & 68 & 44 & 73.33 & 112 & 70 & 0.318 \\
\hline Female & 32 & 32 & 16 & 26.67 & 48 & 30 & \\
\hline \multicolumn{8}{|l|}{ Access to market } \\
\hline Yes & 90 & 90 & 55 & 73.33 & 145 & 90.625 & 0.031 \\
\hline No & 10 & 10 & 5 & 26.67 & 15 & 9.375 & \\
\hline \multicolumn{8}{|l|}{ Access to credit } \\
\hline Yes & 11 & 11 & 1 & 1.67 & 12 & 7.5 & 0.974 \\
\hline No & 89 & 89 & 59 & 98.33 & 148 & 97.5 & \\
\hline \multicolumn{8}{|l|}{ Field day participation } \\
\hline Yes & 25 & 25 & 1 & 1.67 & 26 & 83.75 & $6.087 * * *$ \\
\hline No & 75 & 75 & 59 & 98.33 & 134 & 16.25 & \\
\hline \multicolumn{8}{|l|}{ Access to information } \\
\hline Yes & 88 & 88 & 33 & 55 & 121 & 75.625 & $12.175^{* * *}$ \\
\hline No & 12 & 12 & 27 & 45 & 39 & 24.375 & \\
\hline \multicolumn{8}{|l|}{ Education level } \\
\hline Illiterate & 50 & 50 & 50 & 83.33 & 100 & 62.5 & \multirow{5}{*}{$13.196 * * *$} \\
\hline Grad 1-4 & 39 & 39 & 9 & 15 & 48 & 30 & \\
\hline Grad 5-8 & 10 & 10 & 1 & 1.67 & 11 & 6.875 & \\
\hline Grad 9-12 & 1 & 1 & - & - & 1 & 0.625 & \\
\hline Certificate and above & - & - & - & - & - & - & \\
\hline
\end{tabular}

Source: Own Survey result August 2020

Table 2. Binary Logit estimates of adoption of improved sorghum varieties

\begin{tabular}{|c|c|c|c|}
\hline Independent Variables & Estimated coefficient & Odds ratio & Wald statistics \\
\hline constant & -6.176 & - & 3.648 \\
\hline Sex & -0.711 & 0.491 & 0.883 \\
\hline Age & $-0.156^{* * *}$ & 0.855 & 5.017 \\
\hline Edu. Level & $2.086 * * *$ & 8.054 & 5.198 \\
\hline Farm. size & $1.145 * * *$ & 3.143 & 14.364 \\
\hline Dependent member & $-0.437 *$ & 2.958 & 2.958 \\
\hline Livestock owned & $0.174 * * *$ & 1.191 & 15.523 \\
\hline Active Lab. size & $0.754 * * *$ & 5.712 & 5.712 \\
\hline Access to credit & 0.280 & 1.323 & 0.052 \\
\hline Access to market & 0.760 & 0.467 & 0.396 \\
\hline Off /arm activates & $1.265^{*}$ & 0.282 & 2.958 \\
\hline Field dpart. & $2.218 * *$ & 9.194 & 3.097 \\
\hline Freq. contact with extension agent & $0.695 * * *$ & 2.003 & 11.889 \\
\hline
\end{tabular}

Source: Own Survey result August 2020.

Model chi-square $\left(\mathrm{X}^{2}\right) 134.94 * * *$

Over all, model prediction $80 \%$

Over all prediction of adopters $86 \%$

Over all prediction of non adopters $74.3 \%$

*** represent significance at 1 percent levels. 
Age of households head: The odds ratio of age of household head is 5.017; this implies that, a household head were younger is 5.017 times as likely to be adopter relative to those of older household head. This finding is similar with the study results reported by [10, 14]. Education level of head, the odds ratio of education level of head is 5.198, this implying that a household head whose educated is 5.189 times as likely to be adopter relative to those who is illiterate household heads. This result is supported by the findings of [10]. Farm size: The odds ratio of farm size is $14.364 \mathrm{im}-$ plying that a household head whose has large farm size is 14.364 times as likely to be adopter relative to those who has small farm size. Farm size influenced the adoption of improved sorghum varieties positively and significantly. Off-farm activities: The possible explanation is that those households who have better access to different income sources are more likely to become adopter than those households who has little. That is, households with higher income have strong in put purchasing power so that they can accomplish their improved seed requirements. Livestock holding: has significant effect at $1 \%$ probability level and positive impact on adoption status of the rural household of the study area. Access to information: The odds ratio of access to information is 3.097 implying that a household heads has an access to information is 3.097 times as likely to be adopter relative to those who has not an information access. This finding is similar with the study results reported by $[10,15]$.

Active labor size: significant at less than 1 percent probability level and positively related to households improved Sorghum varieties adoption of the study area. The result indicated that smaller active labor size tends to be non-adopter as compared to larger active labor size. The odds ratio of active labor size is 5.712 . This result supported by $[12,17]$ and Frequency contact with extension agents: The odds ratio of contact with extension agents is 11.889 implying that a household heads has a chance to contact with extension agents is 11.889 times as likely to be adopter relative to those of has not chance to contact with extension agents.

\section{Conclusions}

This paper presents the results of an empirical application of maximum likelihood estimate of Logit model to determine socio-economic factors influencing farmer's adoption of improved Sorghum varieties. The results of the econometric model indicated that farm size, education level, number of active labor of the household, attending field day programs, frequency of contact with extension agent, access to information and number of livestock owned by farmer were significantly influenced the adopter at one percent probability level. Whereas, age of household head and number of dependent member of the household have negative influenced on adoption of improved Sorghum varieties. Generally, to enhance the adoption of improved sorghum varieties, the government should strengthening extension services and increasing farmers engagements on formal education. Additionally, concerned stockholders including nongovernmental organizations should work on full package properly designed field demonstration to increase the adoption rate of improved Sorghum varieties.

\section{References}

[1] Getachew Diriba. (2020). Agricultural and Rural Transformation in Ethiopia. Obstacles, Triggers and Reform Considerations Policy Working Paper 01/2020.

[2] Central Statistical Agency CSA. (2017). Agricultural survey report on area and production of major crops.

[3] UNCTAD. (2017). Global Investment Prospects and Trends. World Investment Report, 58-90.

[4] Diriba, Getachew. (2018). Overcoming Agricultural and Food Crisis. Institutional Evolution and the Path to Agricultural Transformation. USA and Addis Ababa.

[5] Central statistical Agency (CSA). (2018). The federal democratic republic of Ethiopia central statistical agency, agricultural sample survey (2010 E.C.), volume I, report on area and production of major crops (private peasant holdings, meher season) statistical bulletin 586. Addis Ababa, Ethiopia.

[6] Wasihun Gizaw and Desu Assegid. (2020). Trend of cereal crops production area and productivity, in Ethiopia. IJASFT, 12(6), 26-34.

[7] Ethiopian Agricultural Research Organization (EARO). (2004). Directory of released crop varieties and their recommended cultural practices. EARO, Addis Ababa.

[8] MDAO. (2020). Annual report of Mieso district Agricultural Office.

[9] Feder, G., R. E. Just, and D. Zilberman. (1985). Adoption of agricultural innovation in developing countries: A survey of Economic Development and Cultural Change, 33: 255-298.

[10] Mahdi Egge, P. Tongdeelert, S. Rangsipaht, and S. Tudsri. (2012). Factors affecting the adoption of improved sorghum varieties in awbare district of somali regional state, Ethiopia. Kasetsart J. (Soc. Sci)., 33: 152-160.

[11] Tesfaye Getachew. (2008). Characterization of Menz and Afar Indigenous Sheep Breeds of Smallholders and Pastoralists for 
Designing Community-Based Breeding Strategies In Ethiopia. Https://Cgspace.Cgiar.Org/, pp. 76-80.

[12] M. Werteker, et al. (2010). Environmental and Varietal Influences on the Fatty Acid Composition of Rapeseed, Soybeans and Sunflowers. Journal of Agronomy and Crop Science, 196(1), 20-27.

[13] Gujarati, D. N. (2004). Basic Econometrics: fourth edition. Tata McGraw-Hill Publishing Company Limited, New Delhi, pp. 580-625.

[14] Abebaw, D. and Abelay, K. (2001). Factors Influencing adoption of high yielding maize varieties in South Eastern Ethiopia: An application of login Analysis. Quarterly Journal, of International Agriculture, 4(2).

[15] Asfaw Adugna. (2007). The role of introduced sorghum and millets in Ethiopian agriculture. ICRISAT Open Access Journal, 3(1): 1-12. (http://ejournal.icrisat.org) on July 12, 2013.

[16] Amsalu Aklilu and de J. Graaff. (2007). Determinants of adoption and continued use of stone terraces for soil and water conservation in an Ethiopian highland watershed. Ecological Economics, 61(2): 294-302.

[17] Bayissa Gedefa. (2010). Adoption of improved sesame varieties in Meisso district, West Hararghe Zone, Ethiopia. An M.sc Thesis submitted to Haramaya University. P. 108.

[18] Endrias Geta. (2003). Adoption of Improved Potato Varieties in Boloso Sore District, Southern Ethiopia. An M.Sc. Thesis presented to the School of Graduate Studies of Haramaya University, Haramaya Ethiopia. P. 92. 